\title{
Does a Ventilation/Compression Ratio of 5:50 Alter Gas Exchange in Basic Life Support? A Simulation in a BLS-Model of Patients Undergoing General Anesthesia
}

\author{
Clemens Kill ${ }^{*}$, Christian Friedrich, Timon Vassiliou, Leopold Eberhart, Dirk Ruesch and \\ Hinnerk Wulf
}

Department of Anesthesiology and Critical Care, Philipps-University, Marburg, Germany

\begin{abstract}
Background: The goal of Basic Life Support is the oxygenation of vital organs during cardiac arrest. Therefore, chest compressions are combined with ventilation in a fixed ratio. This study investigated the influence of bag $/ \mathrm{mask}$ ventilation on pulmonary gas exchange in anaesthetized patients performed with a ventilation/compression ratio of 2:15 compared to $5: 50$.

Methods: Forty patients scheduled for elective cardiac surgery received general anesthesia (Propofol/Sufentanil/ Rocuronium). Upon loss of consciousness bag/mask ventilation was started (151/min $\mathrm{O}_{2}$ with reservoir bag) over a six minute period using either 2 ventilations every 9 seconds (simulated ventilation/compression ratio 2:15) or 5 ventilations every 30 seconds (simulated ventilation/compression ratio 5:50). Arterial blood gas sampling was performed at beginning of ventilation and after six minutes. Data were analyzed with 2-factorial ANOVA.

Results: Arterial $\mathrm{PO}_{2}$ increased in both groups during the ventilation with pure oxygen $\left(\mathrm{PaO}_{2}: 2: 15\right.$ group: $259 \mathrm{mmHg}$ [0 $\mathrm{min}$ ], $369 \mathrm{mmHg}$ [6 $\mathrm{min}$ ]; 5:50 group: $277 \mathrm{mmHg}$ [0 $\mathrm{min}$ ], $363 \mathrm{mmHg}$ [6 $\mathrm{min}$ ]; n.s.). Arterial $\mathrm{pCO}_{2}$ also increased $\left(\mathrm{PaCO}_{2}:\right.$ 2:15 group: $47 \mathrm{mmHg}$ [0min], $48 \mathrm{mmHg}$ [6min]; 5:50 group: $47 \mathrm{mmHg}$ [0min], $52 \mathrm{mmHg}$ [6min], $\left.\mathrm{P}=0,018\right)$. Consequently, $\mathrm{pH}$ decreased in both groups (pH: 2:15 group; 7,37 [0min], 7,36[6min]; 5:50 group: 7,38 [0min], 7,34 [6min], $\mathrm{P}=0,02)$. There was no critical decrease of $\mathrm{SpO}_{2}$ at any time.

Conclusions: In the anesthetized patient with spontaneous circulation bag/mask ventilation simulating ventilation/compression ratios of 2:15 and 5:50 enable an adequate oxygenation and stable acid base balance.
\end{abstract}

Keywords: Basic life support (BLS), ventilation, chest compression.

\section{BACKGROUND}

Basic Life Support (BLS) guidelines recommend ventilation as well as external chest compressions in a fixed ratio to maintain tissue perfusion and oxygenation during cardiac arrest [1]. While any interruption of chest compressions seems to deteriorate perfusion, there is little information about the frequency and pattern of ventilations required to maintain an adequate oxygenation and to prevent excessive hypercarbia during cardiac arrest [2,3]. The importance of non-interrupted chest compressions lead to the changes in the ILCOR guidelines 2005, that recommend a ventilation/compression ratio of 2:30 instead of 2:15 during Basic Life Support. In this study, a model of the anesthetized patients was chosen to investigate the influence of two different ventilation/compression ratios on pulmonary gas exchange.

\section{METHODS}

After IRB approval, forty patients undergoing elective cardiac surgery were enrolled. Inclusion criteria were as

*Address correspondence to this author at the Department of Anesthesiology and Critical Care, Philipps-University, D-35033 Marburg, Germany; Tel: +4964212865981; Fax: +4964212866996;

E-mail: killc@staff.uni-marburg.de follows: coronary artery bypass graft (CAB), ejection fraction $>50 \%$, absence of signs of a difficult airway based on physical examination (Mallampati Score 1or 2), and absence of any pulmonary disease. After arrival in the operating room patients were randomly allocated to the 2:15-group (simulated ventilation/compression ratio $2: 15$ ) or the 5:50group (simulated ventilation/compression ratio 5:50) using a sealed envelope technique. Patients were monitored with five-lead ECG, pulse-oximetry and invasive arterial blood pressure after canulation of the A. radialis. A first arterial blood sample was drawn while the patients were breathing spontaneously. Anesthesia was induced with sufentanil (0.3$1 \mathrm{mcg} / \mathrm{kg})$ and propofol $(1-2 \mathrm{mg} / \mathrm{kg})$ in both groups. Upon the start of sufentanilinfusion, patients were preoxygenated with pure oxygen via face mask. After loss of consciousness, bag/mask ventilation with a self-inflatable bag (AMBU Mark 3, Ambu®, Denmark) with oxygen reservoir (151 $\left.\mathrm{O}_{2} / \mathrm{min}\right)$ and face mask was started and rocuronium $(1 \mathrm{mg} / \mathrm{kg})$ was administered. The 2:15-group received 2 ventilations every 9 seconds (corresponding to a ventilation/compression ratio of 2:15 when administering 100 compressions/min). The 5:50-group was ventilated with 5 ventilations every 30 seconds (corresponding to a ventilation/compression ratio of 5:50) over a six minute period. Additional ventilations were not allowed. Heart rate was maintained above $50 \mathrm{bpm}$ and 
systolic blood pressure above $80 \mathrm{mmHg}(10.6 \mathrm{kPa})$. Anaesthesia was maintained with propofolinfusion $\left(4 \mathrm{mg}^{*} \mathrm{~kg}^{-1} \mathrm{~h}^{-1}\right)$. Ventilations were performed by anaesthesiologists with at least 3 years professional experience. Arterial blood gases were drawn right after putting in the arterial line (t0), after injection of rocuronium ( $\mathrm{t} 1)$, and after six minutes $(\mathrm{t} 2)$. After the six minute period an endotracheal tube was inserted and the further preoperative routine procedures were performed.

Data were analyzed using students-t-test and 2-factorial ANOVA after confirming a normal distribution using the Kolmogorov-Smirnov-test. A prospective power analysis revealed that 40 patients (20 per group) provide a power of more than $80 \%$ to detect a relative difference of $25 \%$ between the two groups using a type I error of 0.05 and assuming a standard deviation of the two groups of not more than a quarter of the actual mean. Data are presented as means (+/SD).

\section{RESULTS}

All forty patients enrolled in the study could be analysed. No patient had to be excluded from the study due to critical decrease of oxygen saturation, critical hypotension or bradycardia from the beginning of induction until completing the last blood gas sampling.

Patients did not differ in age, gender or body mass index (BMI). The values of $\mathrm{PaO}_{2}, \mathrm{PaCO}_{2}$ and $\mathrm{pH}$ before the experiments (t0) also showed no differences between the groups (Table $\mathbf{1}$ ).

Table 1. Overview of Biometrical Data and Baseline Results (= t0) of Blood Gas Analysis of Both Study Groups $( \pm$ SD)

\begin{tabular}{|l||c|c|c|}
\hline Group & $2: 15$ & $5: 50$ & \\
\hline $\mathbf{N}$ & 20 & 20 & \\
\hline Age [yrs] & $63,2( \pm 10,5)$ & $63,6( \pm 10,6)$ & n.s. \\
\hline Height [cm] & $171( \pm 8)$ & $173( \pm 9)$ & n.s. \\
\hline BMI & $27,4( \pm 3,0)$ & $29,7( \pm 3,9)$ & n.s. \\
\hline $\mathbf{P a O}_{2}(\mathbf{t 0})[\mathbf{m m H g}]$ & $81( \pm 17,1)$ & $79( \pm 12,6)$ & n.s. \\
\hline $\mathbf{P a C O}_{2}(\mathbf{t 0})[\mathbf{m m H g}]$ & $40( \pm 3,5)$ & $40( \pm 2,8)$ & n.s. \\
\hline pH (t0) & $7,43( \pm 0,19)$ & $7,44( \pm 0,29)$ & n.s. \\
\hline
\end{tabular}

n.s. $=$ not significant.

Table 2. Comparison of Results of Blood Gas Analyses After Injection of Rocuronium (t1) and Six Minutes Following Injection of Rocuronium (t2)

\begin{tabular}{|l|c|c|c|}
\hline & T 1(0 min) & T 2(6 min) & \\
\hline \hline $\mathrm{PaO}_{2}$ (2:15-group) $[\mathrm{mmHg}]$ & $259 \pm 101$ & $369 \pm 88$ & \multirow{2}{*}{ n.s. } \\
\cline { 1 - 3 } $\mathrm{PaO}_{2}$ (5:50-group) $[\mathrm{mmHg}]$ & $277 \pm 90$ & $363 \pm 113$ & \\
\cline { 1 - 3 } $\mathrm{PaCO}_{2}$ (2:15-group) $[\mathrm{mmHg}]$ & $47 \pm 3,6$ & $48 \pm 6,3$ & \multirow{2}{*}{$\mathrm{P}=0,018$} \\
\cline { 1 - 3 } $\mathrm{PaCO}_{2}$ (5:50-group) $[\mathrm{mmHg}]$ & $47 \pm 3,7$ & $52 \pm 6,4$ & \\
\cline { 1 - 3 } $\mathrm{pH}(2: 15$-group) & $7,37 \pm 0,4$ & $7,36 \pm 0,4$ & \multirow{2}{*}{$\mathrm{P}=0,02$} \\
\cline { 1 - 3 } $\mathrm{pH}$ (5:50-goup) & $7,38 \pm 0,4$ & $7,34 \pm 0,5$ & \\
\hline
\end{tabular}

Arterial $\mathrm{PO}_{2}$ increased in both groups during the ventilation with pure oxygen. Arterial $\mathrm{pCO}_{2}$ also increased and consequently, $\mathrm{pH}$ decreased in both groups. There was no critical decrease of $\mathrm{SpO}_{2}$ at any time. (Table 2, Figs. (1-3))

\section{DISCUSSION}

This study compared a ventilation/compression ratio of 2:15 and 5:50 in a model of the anesthetized patients undergoing anaesthesia for elective cardiac surgery. Oxygenation and elimination of carbon dioxide could be maintained in both groups without major clinical differences.

There are several studies showing the advantage of prolonged compression periods without interruptions that would be needed for ventilations [4-17]. Most of these investigations were either animal experiments or mathematical analyses to predict the influence of changes in the ventilationcompression ratio. In summary, the following aspects seem to be of importance in finding the "BEST VENTILATION/COMPRESSION RATIO":

1. The total minimal ventilation rate seems to be lower than assumed over the last years, although there are no reliable data of gas exchange in the first minutes of CPR in humans with different ventilation-volumes per time. In the first minutes of CPR by a lay person Hallstrom and colleagues found no differences in outcome even when ventilations were not performed at all [10].

2. Each interruption of cardiac compression seems to worsen the probability for successful defibrillation as well as the outcome, independent of the reason for the interruption (analysis of an automated external defibrillator or ventilation)[13-16]. This might be caused by the sudden decrease of mean and diastolic pressure after stopping chest compressions.

3. The workflow under realistic conditions of resuscitation by a two-rescuer team in the field during the first minutes of initial emergency treatment seems to be strongly influenced by the duration of compression periods. Prolonged compression periods enable an earlier defibrillation as well as the start of ALS procedures and the reduction of emotional stress [17-20].

Considering these aspects together, it must be concluded that longer compression periods of any an alternative ventilation/compression ratio (e.g. 2:30, 5:50, 2:100, 5:100) are advantageous, provided a minimal necessary ventilation is applied [21-23].

Recently published data strengthen the evidence of the need for longer continous compression periods to minimize "hands-off-times", to increase oxygen delivery to vital organs, to avoid deleterious effects of excessive hyperventilation on hemodynamics and to optimize the workflow [20, 24-26]. The need for ventilations in the first minutes of CPR seems to depend on the etiology of cardiac arrest (cardiac vs asphyctic), so it might be difficult to recommend a uniform BLS-strategy without any ventilation for all patients suffering cardiac arrest $[27,28]$.

The goal of this study was to provide further information about the gas exchange during BLS with bag/mask ventila- 

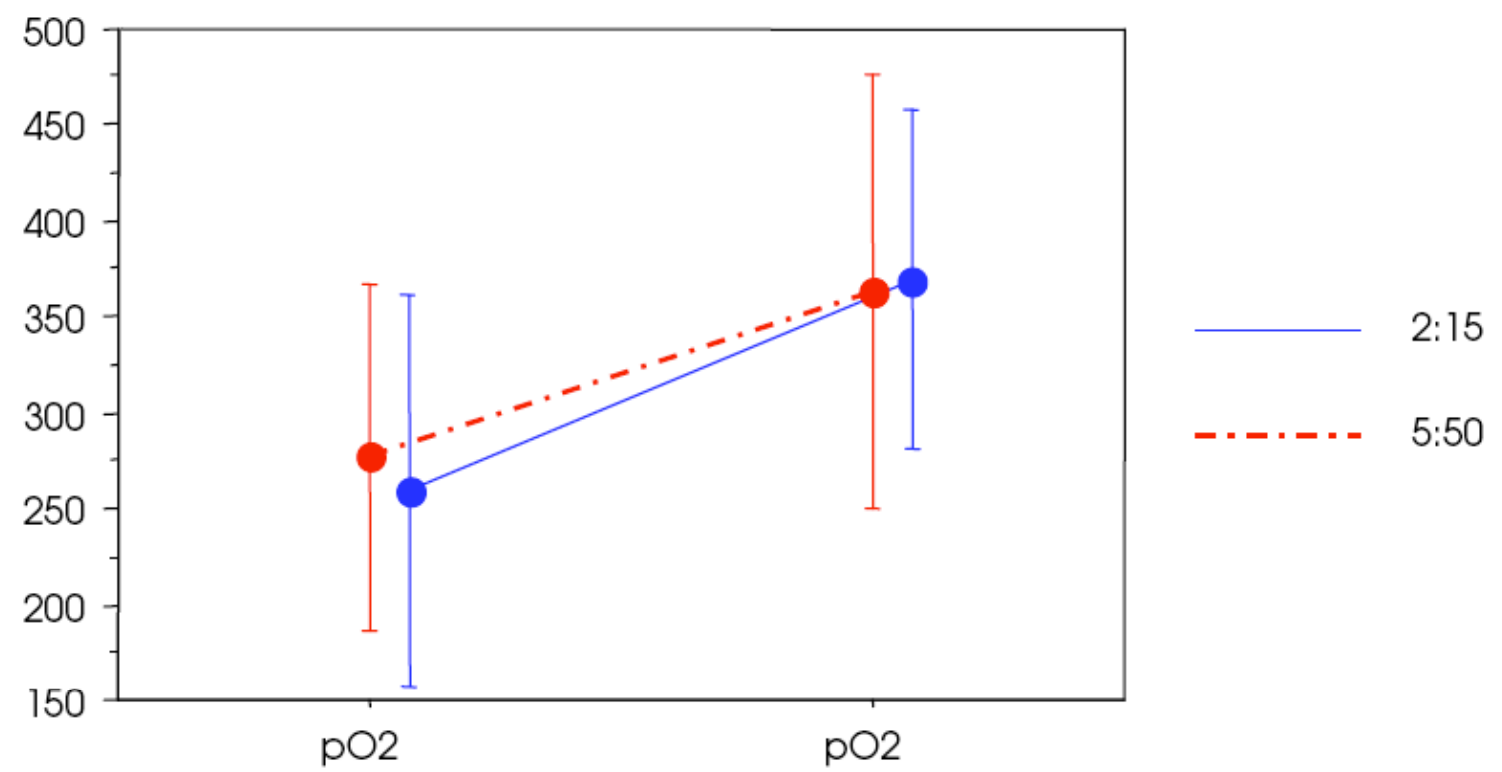

Fig. (1). $\mathrm{PaO}_{2}[\mathrm{mmHg} \pm \mathrm{SD}]$ at $\mathrm{t} 1(0 \mathrm{~min})$ and $\mathrm{t} 2(6 \mathrm{~min})$.

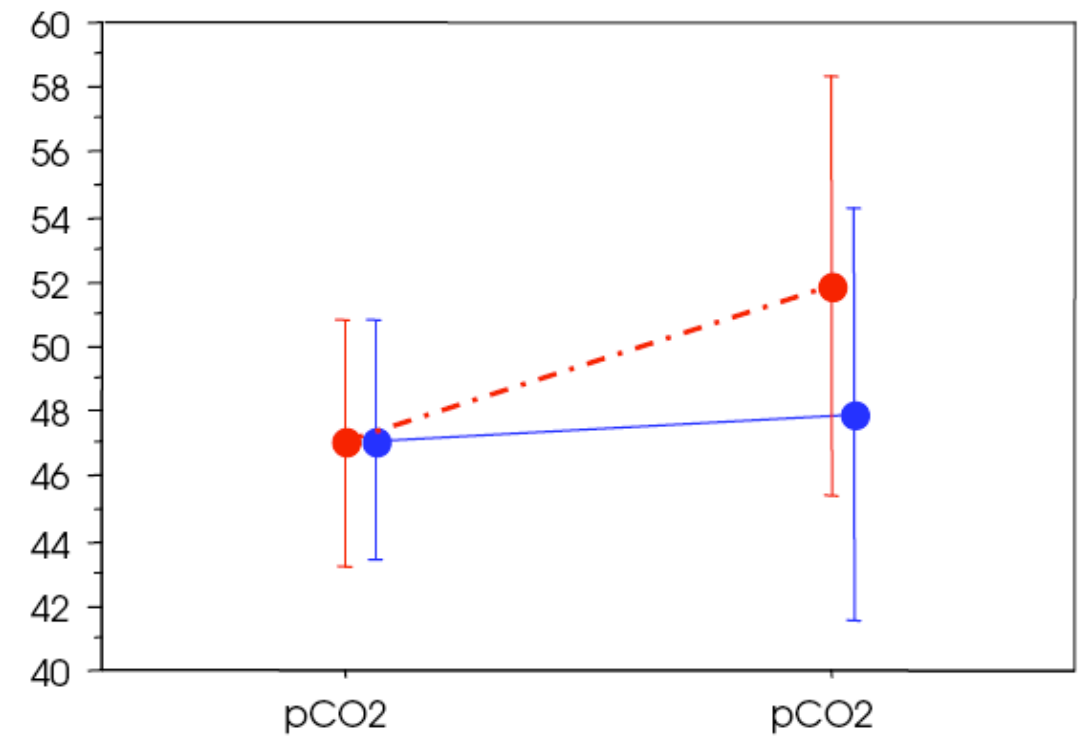

Fig. (2). $\mathrm{PaCO}_{2}[\mathrm{mmHg} \pm \mathrm{SD}]$ at $\mathrm{t} 1(0 \mathrm{~min})$ and $\mathrm{t} 2(6 \mathrm{~min})$.

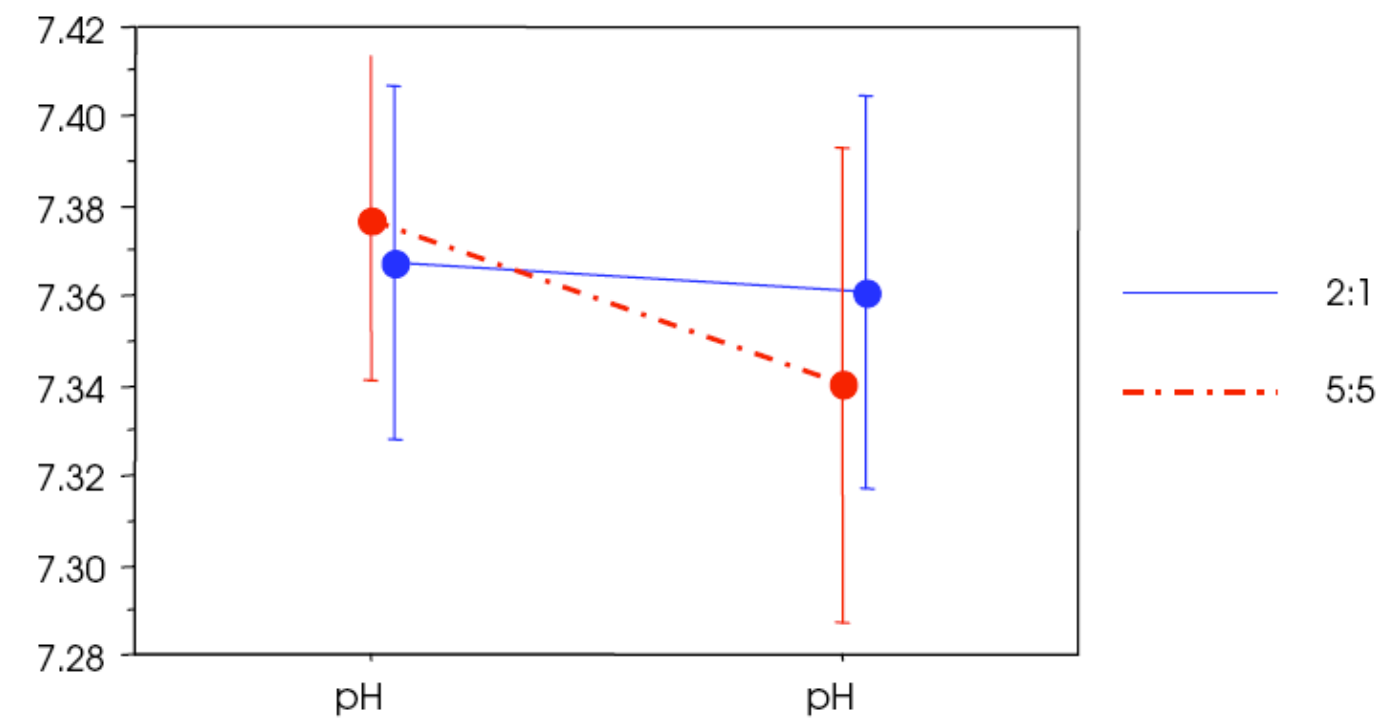

Fig. (3). $\mathrm{pH}[ \pm \mathrm{SD}]$ at $\mathrm{t} 1(0 \mathrm{~min})$ and $\mathrm{t} 2(6 \mathrm{~min})$. 
tion and supplemental oxygen using a prolonged period between ventilations. This concerns the period of Basic Life Support provided by healthcare professionals (EMS, nurses) until the airway can be secured. Research in the field with focus on gas exchange during ongoing resuscitation might be quite difficult to carry out. Therefore, we chose a model of the anesthetized patient with spontaneous circulation. All patients enrolled into this study underwent elective cardiac surgery (CAB), so they belong to a population of patients of enhanced risk for sudden cardiac death and might provide similar conditions for the face mask placement. Unlike resuscitation training mannequins, these patients with their anatomical variations represent most realistic conditions concerning possible difficulties in placing and tightening the face mask for bag/mask ventilation. To avoid bias caused by untrained personnel ventilations were performed by anesthesiologists with at least 3 years professional experience. The six minute period of bag/mask ventilation was chosen to reach at least double the average necessary time period of Basic-Life-Support with an unsecured airway [20]. Ventilation with a self-inflatable bag was chosen because it caused the same difficulties in applying adequate ventilation volumes as it occurs in real emergency situations. We assumed, that several ventilation attempts in a row (as in 5:50) might lead to higher tidal volumes than only two ventilations (as in $2: 15$ ) and therefore lead to results, that might be different to theoretically calculated values.

The results show that using a self-inflatable bag with high oxygen concentration the oxygenation is favourable in both groups without statistical differences. Although the $\mathrm{PaCO}_{2}$ increases slightly more in the 5:50-group after six minutes, these results might be without clinical relevance because a $\mathrm{PaCO}_{2}$ of $51 \mathrm{mmHg}$ could be tolerated as well as the decrease of $\mathrm{pH}$ to 7,33 in the 5:50 group.

There are limitations to the interpretation of these results because all patients had spontaneous circulation. We do not know whether these results can simply be transferred to the situation during cardiac arrest, because pulmonary perfusion under external chest compression might be quite different from spontaneous circulation. The results under comparable pulmonary perfusion of spontaneous circulation show no relevant disadvantage concerning gas exchange of the 5:50 ventilation/compression ratio. If there are differences between the 2:15 and 5:50 group in pulmonary perfusion during cardiac arrest with chest compressions, existing data suggest that perfusion gets better the longer the compression interval will be. Probably the improved perfusion using 50 non-interrupted compressions may also further improve pulmonary gas exchange during $\mathrm{CPR}$.

In conclusion, the advantages of a prolonged ventilation/compression ratio of 5:50 do not seem to be limited by any deterioration in gas exchange. The results of oxygenation and acid-base balance in this investigation under spontaneous circulation might even allow a further reduction of the number of ventilations $(3: 50,2: 50,5: 100$ e.g.) without critical decrease of $\mathrm{PaO}_{2}$. Therefore future research should focus on the influence of prolonged ventilation/compression ratios during BLS.

\section{REFERENCES}

[1] The International Liaison Committee on Resuscitation: Part 2: Adult basic life support. Resuscitation 2005; 67: 181-201.

[2] Noc M, Weil MH, Tang W, Turner T, Fukui M. Mechanical ventilation may not be essential for initial cardiopulmonary resuscitation. Chest 1995; 1083: 821-7.

[3] Chandra NC, Gruben KG, Tsitlik JE, et al. Observations of ventilation curing resuscitation in a canine model. Circulation 1994; 90: 3070-5.

[4] Berg RA, Kern KB, Hilwig RW, Ewy GA. Assisted ventilation during 'bystander' $\mathrm{CPR}$ in a swine acute myocardial infarction model does not improve outcome. Circulation 1997; 96: 4364-71.

[5] Berg RA, Kern KB, Hilwig RW, et al. Assisted ventilation does not improve outcome in a porcine model of single-rescuer bystander cardiopulmonary resuscitation. Circulation 1997; 95: 1635-41.

[6] Kern KB, Hilwig RW, Berg RA, Ewy GA. Efficacy of chest compression-only BLS CPR in the presence of an occluded airway. Resuscitation 1998; 39: 179-88.

[7] Berg RA, Wilcoxson D, Hilwig RW, et al. The need for ventilatory support during bystander CPR. Ann Emerg Med 1995; 26: 342-50.

[8] Sanders AB, Kern KB, Berg RA, Hilwig RW, Heidenreich J, Ewy GA. Survival and neurologic outcome after cardiopulmonary resuscitation with four different chest compression-ventilation ratios. Ann Emerg Med 2002; 40(6): 571-4.

[9] Kern KB, Hilwig RW, Berg RA, Sanders AB, Ewy GA. Importance of continuous chest compressions during cardiopulmonary resuscitation: improved outcome during a simulated lay-rescuer scenario. Circulation 2002; 105(5): 645-9.

[10] Hallstrom A, Cobb L, Johnson E, Copass M. Cardiopulmonary resuscitation by chest-compression alone or with mouth-to-mouth ventilation. N Engl J Med 2000; 342: 1546-53.

[11] Turner I, Turner S, Armstrong V. Does the compression to ventilation ratio affect the quality of CPR: a simulation study. Resuscitation 2002; 52(1): 55-62.

[12] Babbs CF, Kern KB. Optimum compression to ventilation ratios in CPR under realistic, practical conditions: a physiological and mathematical analysis. Resuscitation 2002; 54(2): 147-57.

[13] Berg RA, Sanders AB, Kern KB, et al. Adverse hemodynamic effects of interrupting chest compressions for rescue breathing during cardiopulmonary resuscitation for ventricular fibrillation cardiac arrest. Circulation 2001; 104(20): 2465-70.

[14] Yu T, Weil MH, Tang W, et al. Adverse outcomes of interrupted precordial compression during automated defibrillation. Circulation 2002; 106(3): 368-72.

[15] Eftestøl T, Sunde K, Steen P. Effects of interrupting precordial compressions on the calculated probability of defibrillation success during out-of-hospital cardiac arrest. Circulation 2002; 105: 22703.

[16] Wik L, Hansen TB, Fylling F, et al. Delaying defibrillation to give basic cardiopulmonary resuscitation to patients with out-of-hospital ventricular fibrillation: a randomized trial. JAMA 2003; 289: 138995.

[17] Wik L, Steen PA. The ventilation/compression ratio influences the effectiveness of two rescuers advanced cardiac life support on a manikin. Resuscitation 1996; 31: 113-9.

[18] Dorph E, Wik L, Steen PA. Effectiveness of ventilationcompression ratios $1: 5$ and 2:15 in simulated single rescuer paediatric resuscitation. Resuscitation 2002; 54: 259-64.

[19] Kill C, Friedrich C, Vassiliou T, Geldner G, Wulf H. Advantages of longer compression intervals during Basic Life Support. Resuscitation 2004; 60: 231-2.

[20] Kill C, Giesel M, Eberhart L, Geldner G, Wulf H. Differences in time to defibrillation and intubation between two different ventilation/compression ratios in simulated cardiac arrest. Resuscitation 2005; 65(1): 45-8.

[21] Safar P, Bircher N, Pretto E Jr, et al. Reappraisal of mouth-tomouth ventilation during bystanderinitiated CPR. Circulation 1998; 98: 608-10.

[22] Idris AH, Banner MJ, Wenzel V, Fuerst RS, Becker LB, Melker RJ. Ventilation caused by external chest compression is unable to sustain effective gas exchange during CPR: a comparison with mechanical ventilation. Resuscitation 1994; 28: 143-50. 
[23] Idris AH, Wenzel V, Becker LB, Banner MJ, Orban DJ. Does hypoxia or hypercarbia independently affect resuscitation from cardiac arrest? Chest 1995; 108: 522-8.

[24] Heidenreich JW, Higdon TA, Kern KB, et al. Single-rescuer cardiopulmonary resuscitation: ,two quick breaths'--an oxymoron. Resuscitation 2004; 62: 283-9.

[25] Alem AP van, Sanou BT, Koster RW. Interruptions of cardiopulmonary resuscitation with the use of the automated external defi- brillator in out-of-hospital cardiac arrest. Ann Emerg Med 2003; 42: 449-57.

[26] Aufderheide TP, Sigurdsson G, Pirrallo RG, et al. Hyperventilation-induced hypotension during cardiopulmonary resuscitation. Circulation 2004; 109(16): 1960-5.

[27] Weil MH, Tang W, Bisera J. Cardiopulmonary Resuscitation - One Size Does Not Fit All. Circulation 2003; 107: 794-6.

[28] Weisfeldt ML, Becker LB. Resuscitation after cardiac arrest: a 3phase time-sensitive model. JAMA 2003; 288: 3035-8.

Received: January 23, 2008

Revised: March 26, 2008

Accepted: March 28, 2008

(C) Kill et al.; Licensee Bentham Open.

This is an open access article distributed under the terms of the Creative Commons Attribution License (http://creativecommons.org/licenses/by/2.5/), which permits unrestrictive use, distribution, and reproduction in any medium, provided the original work is properly cited. 